\title{
Development of a pharmacoeconomic registry: an example using hormonal contraceptives
}

\author{
Annesha White ${ }^{1,2^{*}}$, Meenakshi Srinivasan ${ }^{1 \dagger}$, La Marcus Wingate ${ }^{3}$, Samuel Peasah ${ }^{4}$ and Marc Fleming ${ }^{1}$
}

\begin{abstract}
Background: Disease-specific registries, documenting costs and probabilities from pharmacoeconomic studies along with health state utility values from quality-of-life studies could serve as a resource to guide researchers in evaluating the published literature and in the conduct of future economic evaluations for their own research. Registries cataloging economic evaluations currently exist, however they are restricted by the type of economic evaluations they include. There is a need for intervention-specific registries, that document all types of complete and partial economic evaluations and auxiliary information such as quality of life studies. The objective of this study is to describe the development of a pharmacoeconomic registry and provide best practices using an example of hormonal contraceptives.
\end{abstract}

Methods: An expert panel consisting of researchers with expertise in pharmacoeconomics and outcomes research was convened and the clinical focus of the registry was finalized after extensive discussion. A list of key continuous, categorical and descriptive variables was developed to capture all relevant data with each variable defined in a data dictionary. A web-based data collection tool was designed to capture and store the resulting metadata. A keyword based search strategy was developed to retrieve the published sources of literature. Finally, articles were screened for relevancy and data was extracted to populate the registry. Expert opinions were taken from the panel at each stage to arrive at consensus and ensure validity of the registry.

Results: The registry focused on economic evaluation literature of hormonal contraceptives used for contraception. The registry consisted of 65 articles comprising of 22 cost-effectiveness analyses, 9 cost-utility analyses, 7 costbenefit analyses, 1 cost-minimization, 14 cost analyses, 10 cost of illness studies and 2 quality of life studies. The best practices followed in the development of the registry were summarized as recommendations. The completed registry, data dictionary and associated data files can be accessed in the supplementary information files.

(Continued on next page)

\footnotetext{
*Correspondence: Annesha.White@unthsc.edu

${ }^{\dagger}$ Annesha White and Meenakshi Srinivasan contributed equally to this work.

${ }^{1}$ University of North Texas System College of Pharmacy, University of North Texas Health Science Center, Fort Worth, TX 76107, USA

${ }^{2}$ Department of Pharmacotherapy, UNT System College of Pharmacy, 3500

Camp Bowie Blvd, IREB 211, Fort Worth, TX 76107, USA

Full list of author information is available at the end of the article
}

C C The Author(s). 2021 Open Access This article is licensed under a Creative Commons Attribution 4.0 International License, which permits use, sharing, adaptation, distribution and reproduction in any medium or format, as long as you give appropriate credit to the original author(s) and the source, provide a link to the Creative Commons licence, and indicate if changes were made. The images or other third party material in this article are included in the article's Creative Commons licence, unless indicated otherwise in a credit line to the material. If material is not included in the article's Creative Commons licence and your intended use is not permitted by statutory regulation or exceeds the permitted use, you will need to obtain permission directly from the copyright holder. To view a copy of this licence, visit http://creativecommons.org/licenses/by/4.0/. The Creative Commons Public Domain Dedication waiver (http://creativecommons.org/publicdomain/zero/1.0/) applies to the data made available in this article, unless otherwise stated in a credit line to the data. 


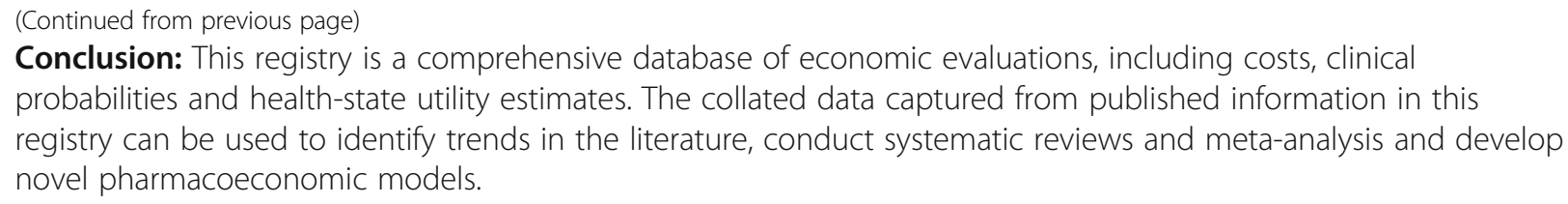

Keywords: Pharmacoeconomic registry, Hormonal contraceptives

\section{Background}

In the field of health outcomes research, disease registries have been useful to collect clinical data, track patients over time and provide information for determining disease progression, safety and effectiveness. A registry is defined as "an organized system that uses observational study methods to collect uniform data (clinical and other) to evaluate specified outcomes for a population defined by a particular disease, condition or exposure, and that serves a predetermined scientific, clinical or policy purpose(s)" [1]. While the importance of clinically focused patient registries is well-defined, supplementing these registries with economic and quality of life (QOL) data provide an opportunity to assess cost-effectiveness of various interventions [2]. In contrast to patient registries, clinical trial outcome databases capture summary-level information from published randomized control trials (RCTs) and observational studies which can be used to perform network and model-based meta-analyses of safety and efficacy parameters [3]. The growth of the pharmacoeconomic literature over the past few decades has prompted several organizations to create databases or registries to compile key variables in published economic evaluations. Examples of current economic databases include the National Health Service (NHS) Economic Evaluations Database [4], Tufts CEA registry [5, 6], Tufts Global Health DALY (Disability-Adjusted Life Year) Registry [7], Pediatric Economic Database Evaluation Project [8], European Network of Health Economic Evaluation Databases (EURONHEED) [9] and the WHO Cost-Effectiveness and Strategic Planning (WHO-CHOICE) [10] databases. These registries are broad in their scope and represent economic evaluations conducted on a variety of healthcare, pharmaceutical and device interventions. Some of the aforementioned databases include different types of economic evaluations [4], while others are specific to cost-utility analysis [5] or cost per DALY studies [7]. However, there are only a few examples of comprehensive conditionspecific health economic model registries, such as the Mount Hood Diabetes Challenge Network [11, 12]. Therefore, we sought to supplement the clinical literature on hormonal contraceptives $(\mathrm{HC})$ with literature on all published complete and partial economic evaluations. Hormonal contraceptives were selected as a focus for a pharmacoeconomic registry for several reasons.
Globally, around 99 million pregnancies were unintended in 2010-2014 [13]. In the United States, nearly $45 \%$ of all pregnancies were unintended in 2011 [14]. Unintended pregnancies represent a major economic burden to the US public insurance programs, estimated to be $\$ 21$ billion in 2010 [15]. In developing countries, women having an unmet need of contraceptives contribute to $84 \%$ of all unintended pregnancies, whereas the remaining occur among contraception users [16]. The reasons for contraception failure depend upon the inherent efficacy of the method, non-adherence, imperfect use, frequency of intercourse and age of the woman [17]. However, consistent use of contraceptives, still results in around 5\% of unintended pregnancies in the USA [18]. Around 151 million women of reproductive age use hormonal contraceptive pills worldwide [19]. Recognizing the large public health implications, the FDA, the pharmaceutical industry and academia have focused efforts towards understanding the role of drug-drug interactions (DDIs) on HC failure [20]. Challenged by a lack of data on the clinical effect of DDIs associated with $\mathrm{HCs}$, efforts are underway to study the impact of DDIs on $\mathrm{HC}$ failure from a multi-disciplinary perspective, including pharmacometrics, pharmacoepidemiology and pharmacoeconomics [21]. In order to evaluate the financial implications of unintended pregnancies resulting from drug-drug interactions with $\mathrm{HCs}$, information was collated from all complete and partial economic evaluations on HCs. The present paper describes how the pharmacoeconomic clinical registry was developed and implemented, detailing its strengths and limitations with the aim of facilitating the creation of other condition specific pharmacoeconomic clinical registries. The registry structure and content are also presented along with best practice recommendations.

\section{Methods}

This study was registered with the International Prospective Register of Systematic Reviews (PROSPERO CRD 42019118036) in January 2019. An expert panel consisting of researchers with expertise in pharmacoeconomics and outcomes research was convened. Based on the specific clinical question of pharmacoeconomics of $\mathrm{HCs}$, the general approach to develop the registry was outlined. 


\section{Environmental scan and study selection}

A keyword-based search strategy was developed to identify relevant articles from PubMed and EMBASE. The search strategy was limited to consider women of reproductive age using hormonal contraceptives for the purpose of contraception, with the comparator being any other method of contraception or non-use of contraception. Studies assessing the impact of family planning interventions where the costs of contraceptives were aggregated, as well as studies that were economic evaluations of $\mathrm{HCs}$ for the management of other conditions such as heavy menstrual bleeding and emergency contraception were excluded. Details of the search strategy and keywords used can be found in Additional file 1. The search was limited to original research studies published in English prior to and including December 2019. Review articles, letters, editorials, commentaries and conference abstracts were excluded. Once duplicate citations were removed, all remaining titles and abstracts were screened by MS and categorized as being relevant, potentially relevant or not relevant. The potentially relevant full-text articles were then reviewed with AW and judged for relevance to be included in the registry. Additionally, hand-searching reference list of articles retrieved were screened to identify relevant economic evaluations. The relevant articles included complete economic evaluations namely, costeffectiveness analyses (CEA), cost-utility analyses (CUA), cost-benefit analyses (CBA) and cost-minimization analysis (CMA). Partial economic evaluations included cost of illness or cost of unintended pregnancy (COUP), cost analyses (CA) and quality of life (QOL) studies. Studies classified as COUP provided country-wide estimates of the costs attributable to unintended pregnancy. The CA studies provided estimates of cost of the intervention without considering outcomes and the QOL studies measured health state utility values of unintended pregnancy. The Preferred Reporting Items for Systematic Reviews and Meta-Analysis (PRISMA) guidelines for developing literature search were followed.

\section{Variable selection and data dictionary}

A list of variables to be included in the registry was developed after careful discussions with the expert panel. It was decided to match variables to the type of study (CEA, CUA, CBA, CMA, COUP, CA, QOL). The registry therefore included general bibliographic variables and information on the funding source, country and region. The variables extracted from studies included: 1) study objective; 2) intervention and comparator; 3) target population characteristics; 4) currency and year; 5) sample size; 6) perspective; 7) source of cost data; 8) direct cost components and amount; 9) non-medical cost components and amount; 10) indirect cost components and amounts;
11) outcome measure; 12) source of outcome data; 13) time horizon; 14) discounting and adjustment of costs; 15) scenario analysis; 16) modeling method description; 17) assumptions; 18) sensitivity analysis; 19) conclusions and 20) limitations. Variables from existing registries were used as guides in the variable development process [4-7]. Based on the type of economic study, other variables such as cost-benefit ratio, average cost-effectiveness (utility) ratio, incremental cost-effectiveness (utility) ratios, and qualityadjusted life-year (QALY) were catalogued. For COUP studies, we included variables to document the total number of unintended pregnancies and costs to the payer and impact of contraceptive nonadherence on total costs. During the course of data extraction of each article, if additional variables were found to be important for the registry, they were identified and included in the registry (e.g., variables for adjustment of cost of birth to account for mistimed rather than truly unwanted births). The data dictionary was continuously revised during this process to account for the changes and can be accessed in Additional file 2.

\section{Online data interface \& data operationalization for querying}

In order to facilitate entry of data into the registry by members of the expert panel and to collect the resulting data in real-time, an online data entry platform using Google Forms was created. However, to allow for querying the registry each variable was further operationalized, i.e., made either numeric (continuous or categorical) or a text entry (see data dictionary in Additional file 2).

\section{Expert panel verification process}

The verification process included two-steps. After the expert panel members received assigned articles to critique, articles were entered into the registry using the Google Form. A formalized approach to review articles that were uploaded in the registry was used to ensure quality and consistency among all the reviewers. Responses collected were then transcribed in the operationalized database in Microsoft Excel by MS. Finally, AW verified all variables within each article. Discrepancies in entry were then discussed among AW and MS until a consensus could be agreed upon.

\section{Results}

From the 1401 articles that were retrieved from the literature search, excluding duplicates, the pharmacoeconomic registry included 65 articles comprising of 22 CEA, 9 CUA, 7 CBA, 1 CMA, 14 CA, 10 COUP and 2 QOL studies. The PRISMA flow diagram is shown in Fig. 1. 


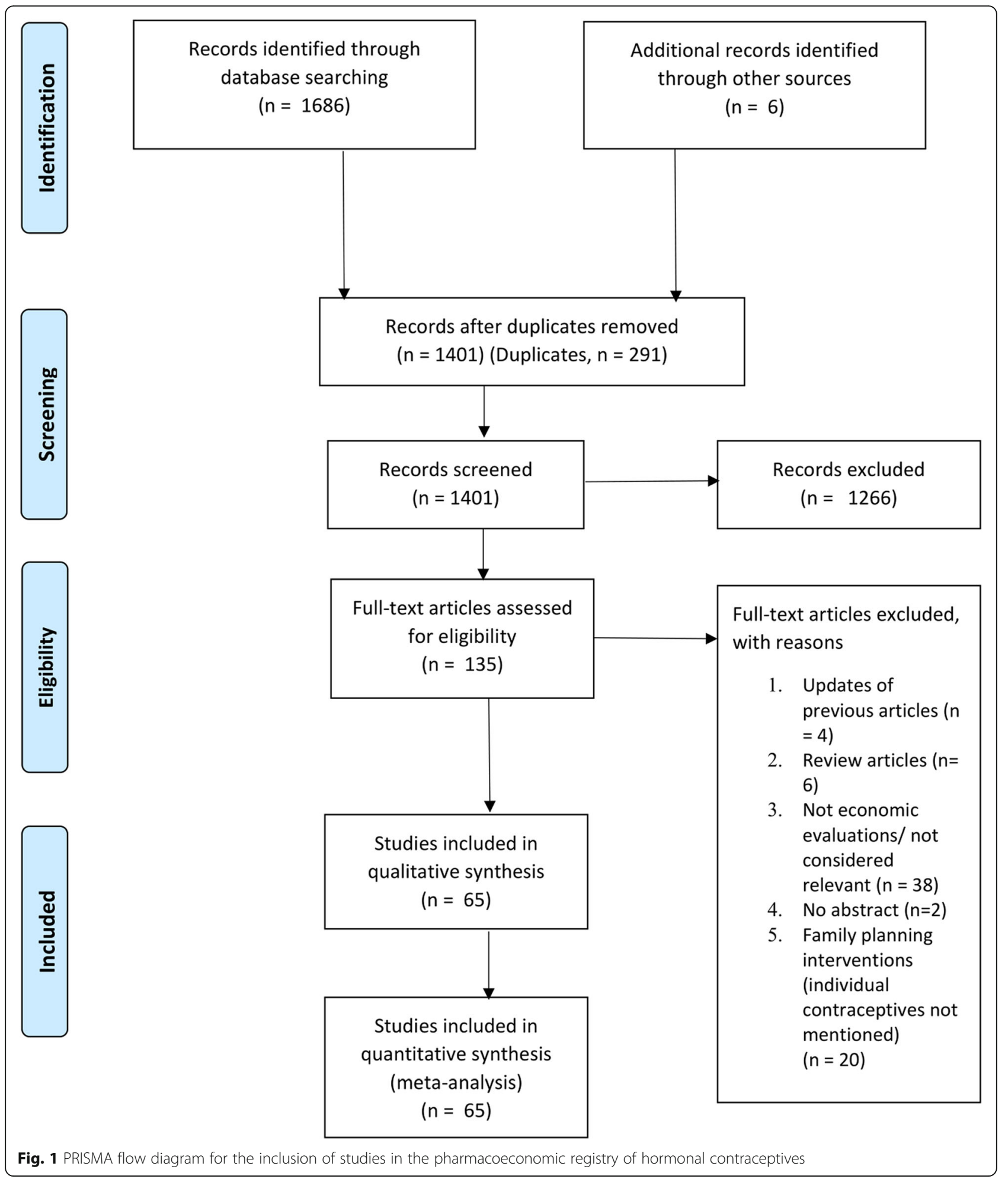

\section{Queries of the pharmacoeconomic registry}

Most of the articles were published in the past 25 years except one from 1972 [22]. The complete registry can be accessed in Additional file 3. The table of cost and probabilities can be accessed in Additional file 4. Table 1 presents a summary of the CEA, CUA, CBA, CMA, CA and QOL studies. From the CEA and CUAs, ten studies were decision-tree models [27, 31, 38-40, 42, 48, 49, 51, 52] and eleven were Markov models [30, 32-34, 37, 41, $44-47,50]$ and one was conducted using a systematic 


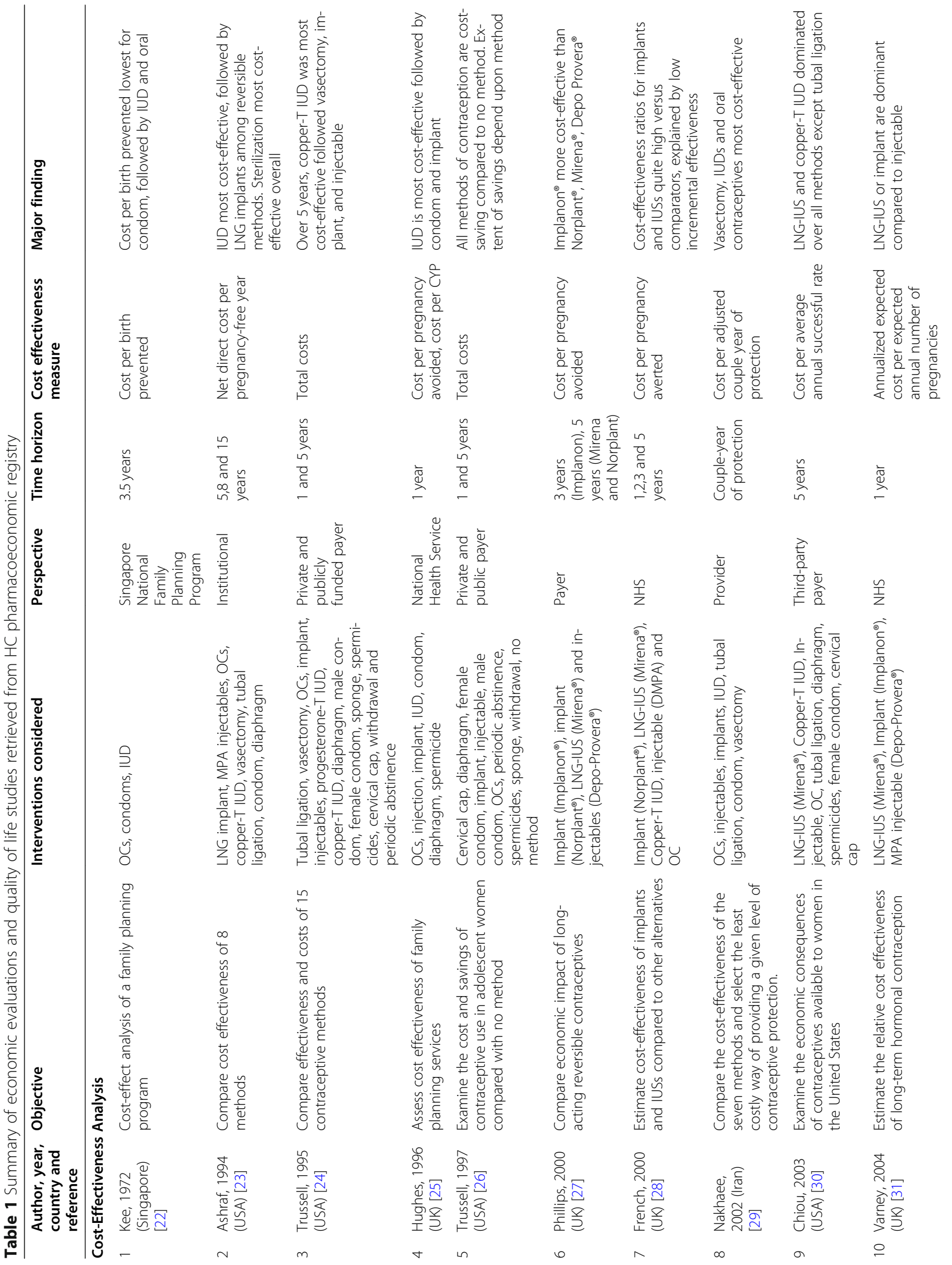




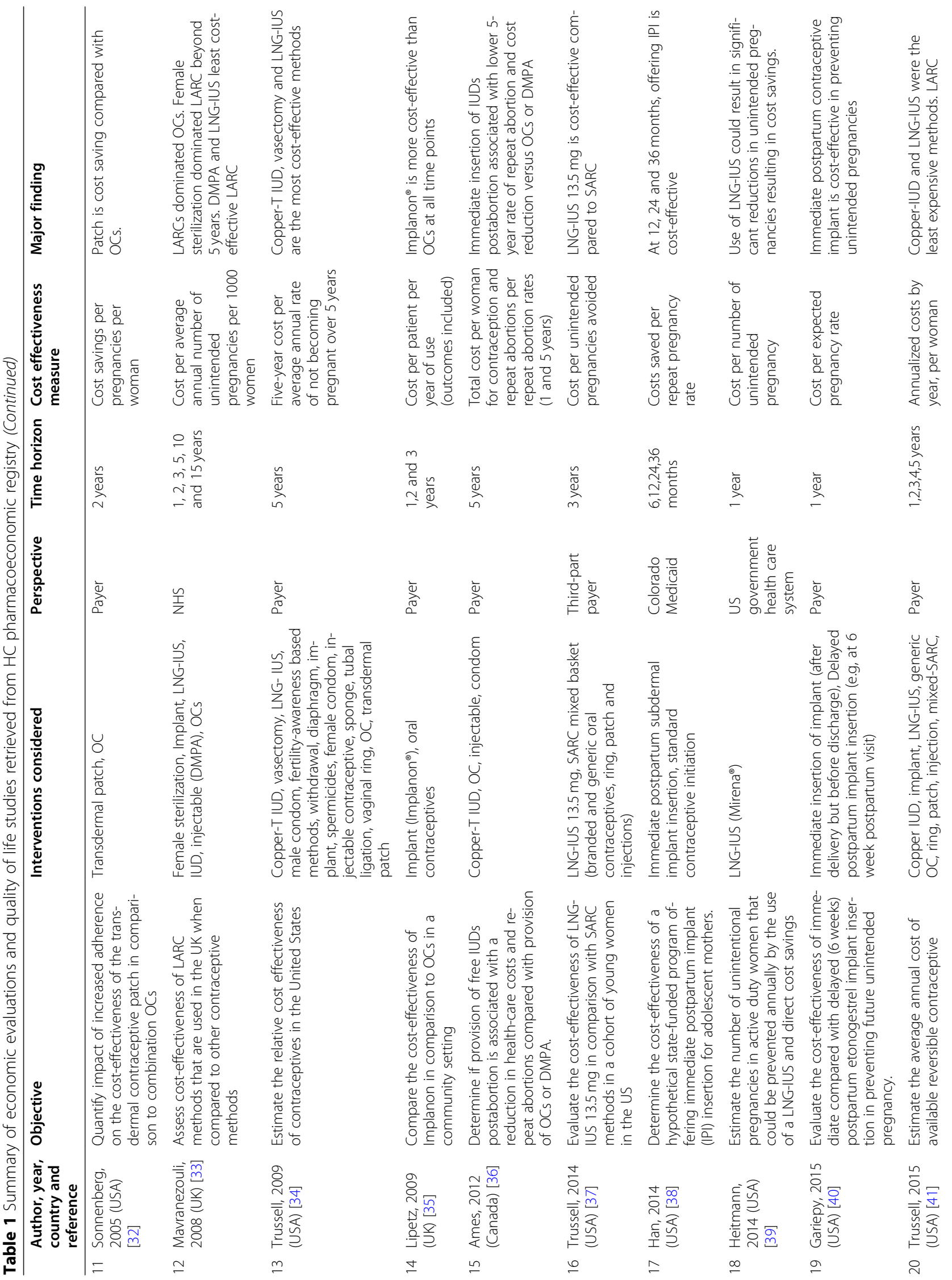




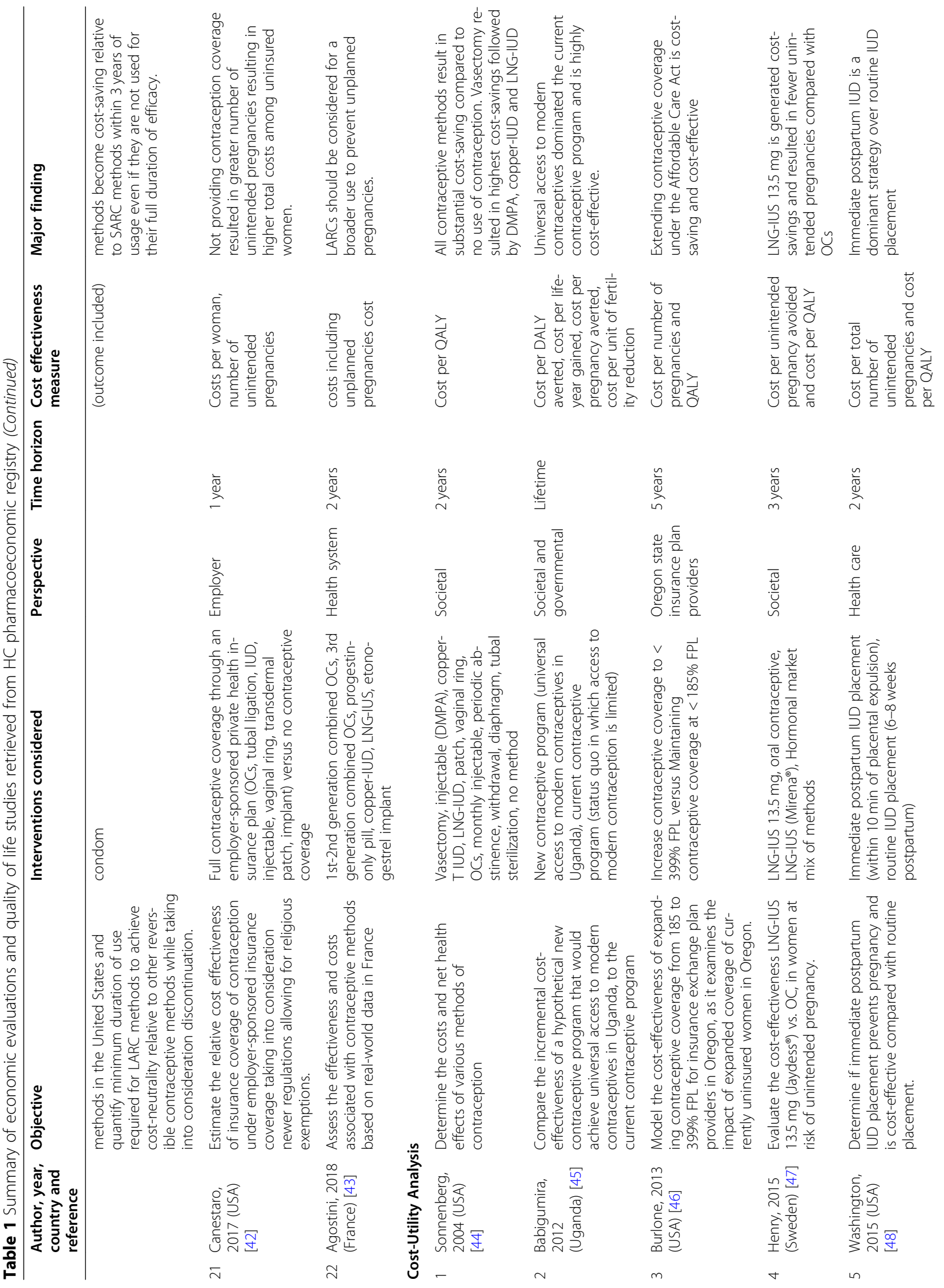




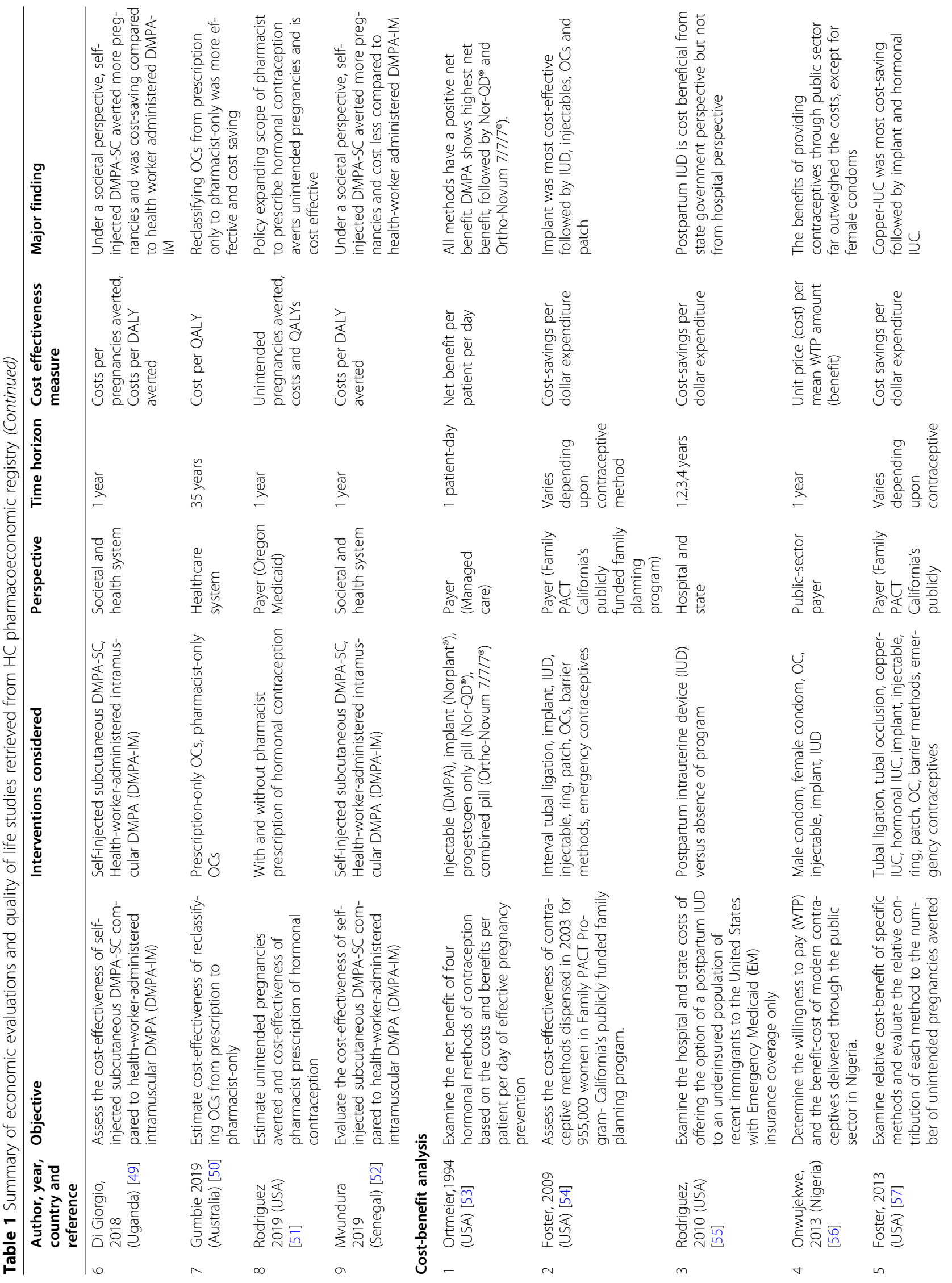




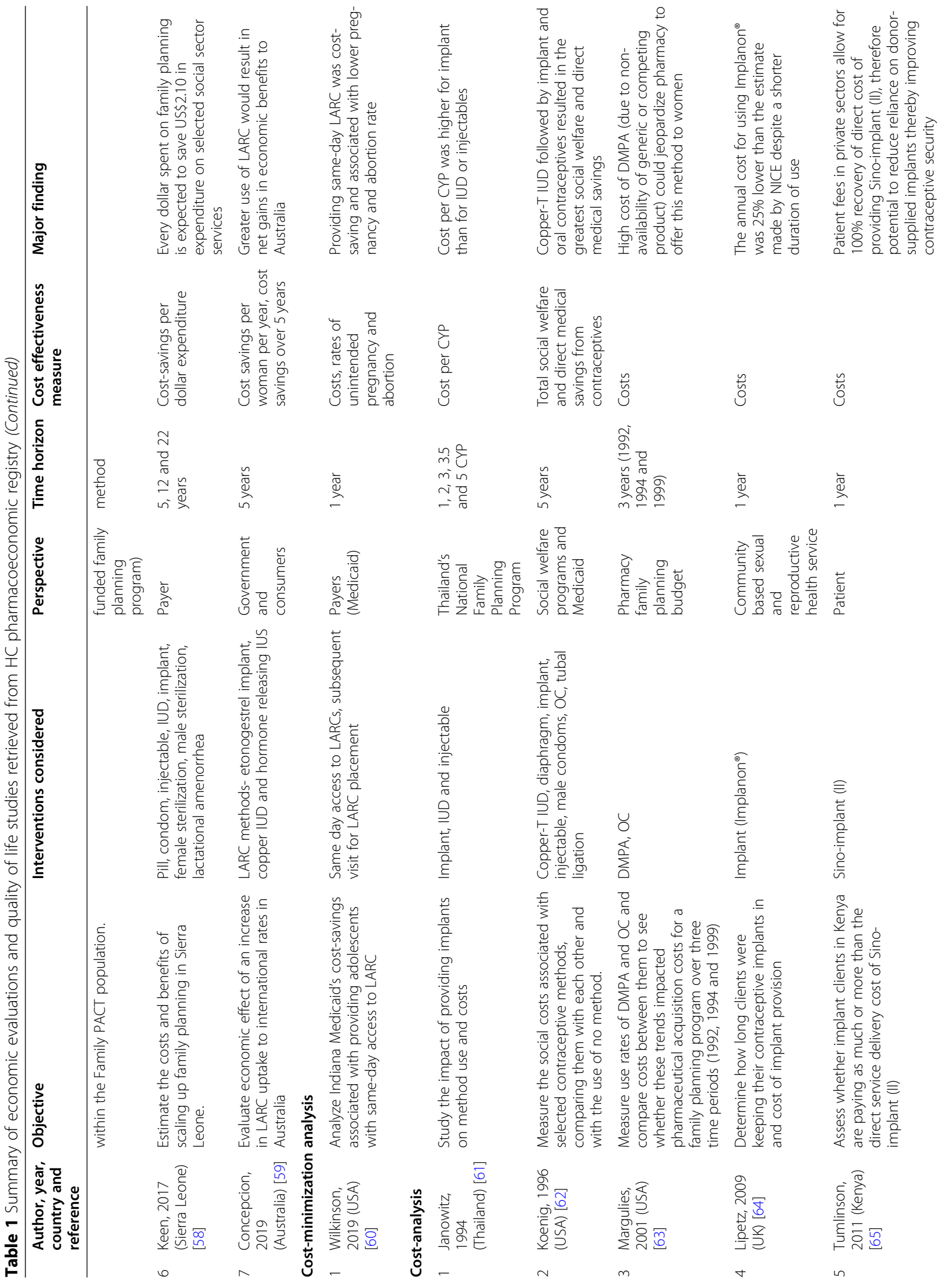




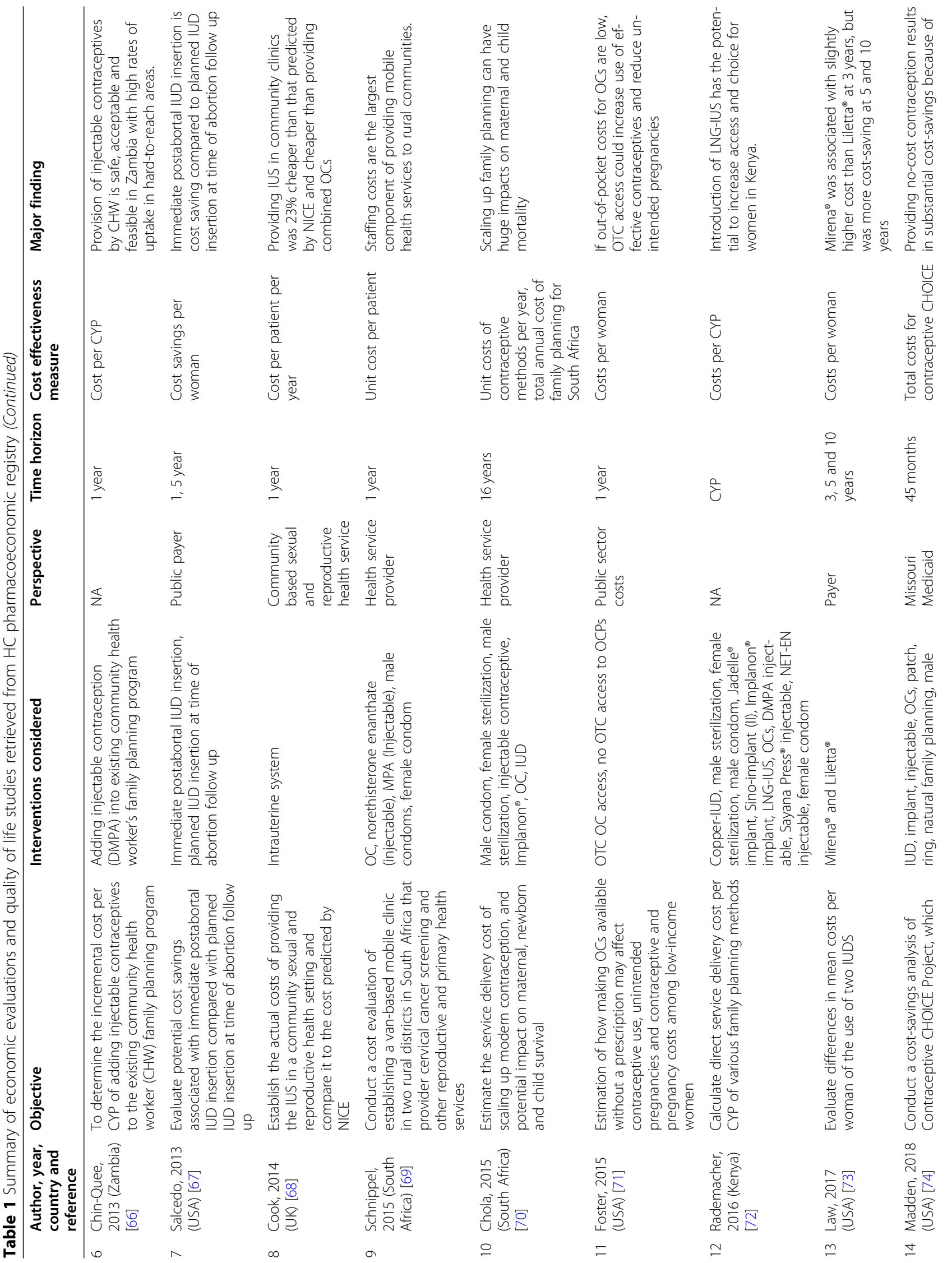




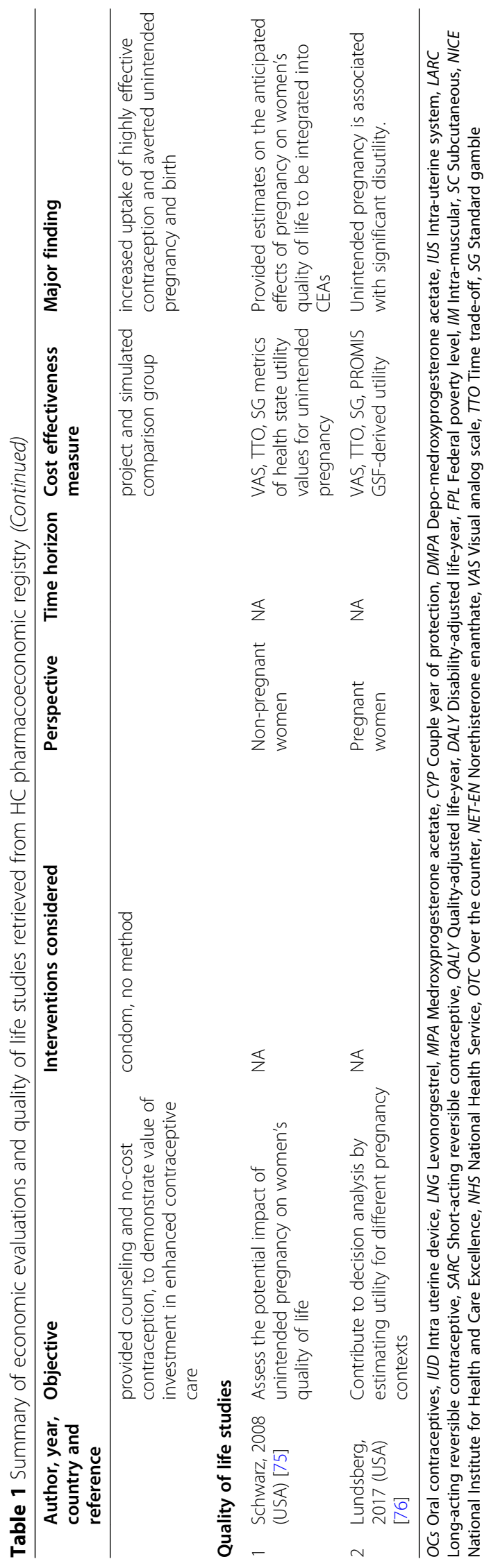


review and meta-analysis as part of a health technology assessment submission [28]. The remaining studies determined cost-effectiveness using real-world data or observational studies [22, 29, 35, 36, 43] or utilized a simple methodology considering costs and failure rates of each method [24-26] or a cost equation for clinical outcomes [23].

Among all the CEA, CUA, CBA, CMA, CA and QOL studies, 29 were conducted among the US population, eight in the UK, two each in Australia, Kenya, South Africa, Uganda and one each from Canada, France, Iran, Nigeria, Senegal, Sierra Leone, Sweden, Thailand, Singapore and Zambia (Table 1). Based on the countrywise distribution, in the published literature there were few economic evaluations conducted in developing countries as compared to developed countries.

While most studies compared the cost-effectiveness of different methods of contraception, some studies addressed more specific issues (Table 1). Seven studies compared the impact of immediate postpartum or postabortion insertion of long-acting reversible contraceptives (LARC) with delayed insertion [36, 38, 40, 48, 55, 60, 67]. Three studies examined the cost-savings from increasing access to oral contraceptives by making available over-the-counter (i.e., without a prescription) or allowing pharmacists to prescribe them [50,51, 71]. Ten studies considered the impact of enhancing access to contraceptives in Africa utilizing novel delivery methods such as community health workers and self-injection $[45,49,52,56,58,65,66,69,70,72]$. Among the studies conducted in US, several focused on populations that faced disparities in access to contraceptives. The majority of studies focused on Medicaid-eligible or lowincome women $[24,26,38,40,51,54,55,57,60,62,63$, $67,71,74]$. Three studies considered adolescent contraceptive provision $[26,38,60]$ and one focused on activeduty military women [39]. Two studies considered the underinsured, quantifying the impact of expansion of contraceptive coverage through Affordable Care Act (ACA) $[42,46]$.

Except for one CBA that determined the willingness-to-pay for contraception [56], all studies considered direct medical costs in their analyses. Direct non-medical costs were considered among six studies [22, 29, 45, 49, 52, 62] and included overhead costs and capital costs, utilization of auxiliary services and social welfare program costs. Indirect costs were considered in eleven studies and included waiting and travel times, productivity losses and personnel training times $[22,35,45,47,49,52,64,70,77-79]$. No study considered the impact of intangible costs. Fifteen studies considered the cost of side effects, out of which seven studies mentioned disaggregated costs of each side effect $[23,24,30,32,34,44,50]$.
Quality of life, in the form of QALY was considered in six of the nine CUAs with the remaining considering DALYs averted (Table 1) [45, 49, 52]. Methodological improvements have occurred over time in the conduct of CUAs, especially with regards to the source of health utility values. In the absence of published estimates, the earliest CUA employed utility values for pregnancy outcomes and other health states that were elicited from a convenience sample of female members of the research team and an advisory panel and these estimates were used in a later CUA $[44,48]$. Recognizing the paucity of reliable utility values for unintended pregnancy, Schwarz et al. [75] conducted a study to assess the potential impact of unintended pregnancy on non-pregnant women. These values were used in subsequently conducted CUAs [46, 47, 50, 51]. In an effort to supplement future CUAs in pregnancy and contraception, Lundsberg et al. measured utility values from a sample of pregnant women for varying contexts such as intention, timing and wantedness (Table 1) [76]. However, the literature is lacking utility values of various pregnancy contexts and outcomes from developing country settings.

Table 2 summarizes the COUP studies. Most of these studies provided country-wide estimates of the burden of unintended pregnancies in the USA [80, 81], Norway [77], Sweden [78], UK [82], Spain [83], South Africa [79], Canada [84] and Russia [85], however, one study estimated these costs for a US employer-sponsored health insurance plan [86]. Imperfect contraceptive adherence contributed to over half of these costs, thus making a case for greater LARC adoption [77, 78, 80, 83, 84].

\section{Purposes of pharmacoeconomic registry and best practice recommendations}

The completed HC pharmacoeconomic registry can serve various purposes to guide future research and policy as mentioned in Table 3. We have used cost implications of DDIs with $\mathrm{HCs}$ as an example to demonstrate how the registry could be used to inform this decision problem. This project was undertaken to systematically document the key variables in all published pharmacoeconomic literature pertaining to HCs. Inclusion of all types of economic articles, including QOL allowed for the creation of an up-to-date compendium, that could aid future researchers and funding agencies in identifying existing research and prioritize future research. Costs, probabilities and utility values documented from each study, including their original references, allows for the collection of input variables for subsequent pharmacoeconomic analyses and budget impact models. Additionally, the registry catalogues the various published model structures, methodologies and assumptions which inform the development of subsequent models. 


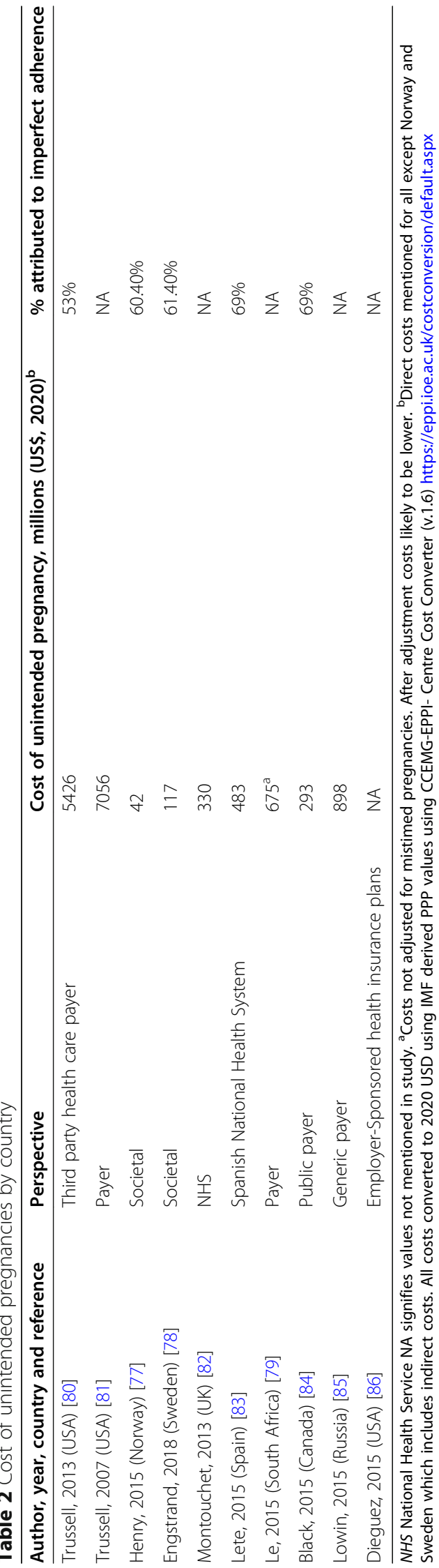




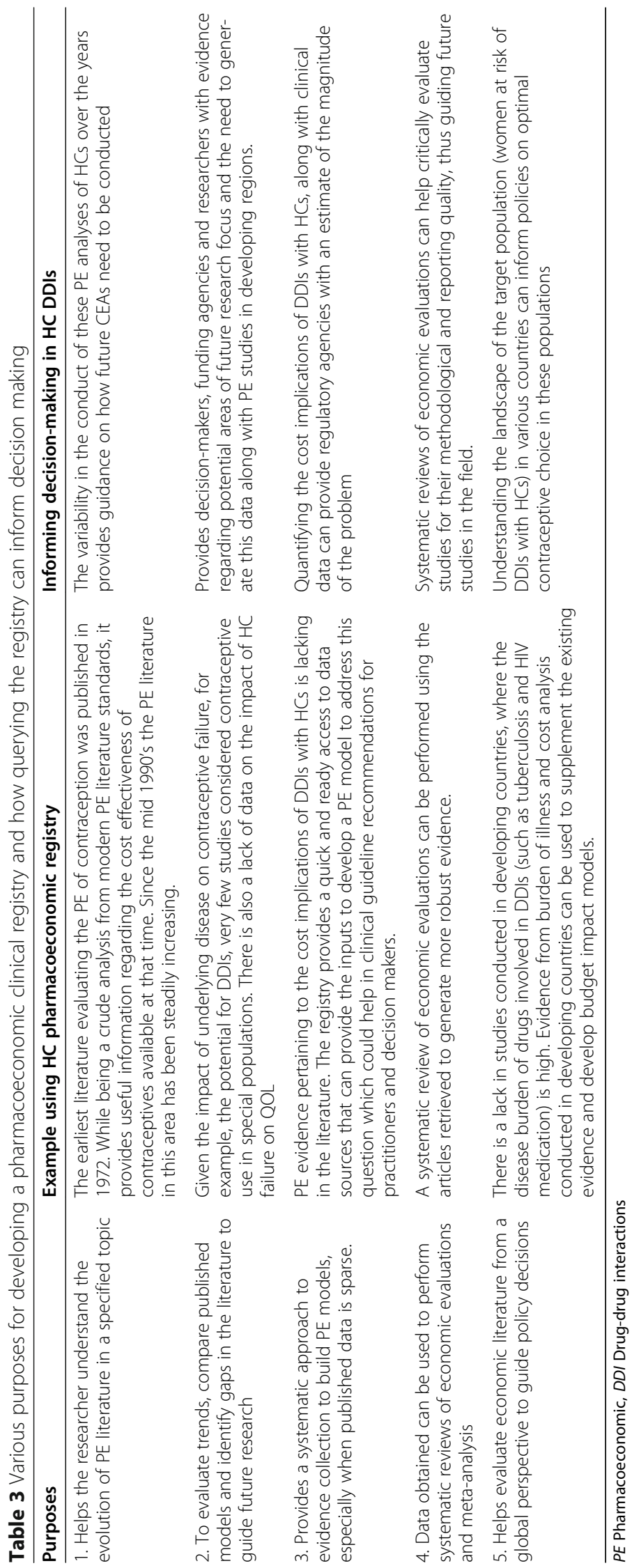


Developing the registry in an iterative manner and using a trial-and-error approach allowed us to identify some of the methodological best practices for the development of a pharmacoeconomic registry which are summarized in Table 4. We recognized the importance of dissemination and transparency of the registry and therefore decided to make it open-access to allow researchers to further improve and use the registry for their own research. Therefore, early planning and engagement with project collaborators, funding agencies, and journals should be undertaken to ensure open availability of the registry. The registry should be well documented by defining each variable in columns and how to read data across rows using an accompanying data dictionary. A core team comprising of experts in fields such as pharmacy, pharmacoeconomics and outcomes research must be assembled to provide continuous feedback on the development and validity of the registry. Variables extracted should be operationalized to allow for querying to the extent desired. Finally, the database must be extensively queried to identify potential transcription errors and areas for improvement. For example, a testing exercise may reveal that a new variable may need to be added in the registry, in that case, the change has to be then made for all prior entered studies.

\section{Discussion}

The article presents the development of a pharmacoeconomic registry using a case study of economic evaluations and QOL studies conducted on $\mathrm{HCs}$ for the purpose of contraception. The best practice recommendations for curating this registry and various cases for use are also presented. The registry included 65 studies, covering a variety of contraceptive interventions across various countries and settings.

One of the major questions that guided the development process was, "How would a potential researcher utilize this resource?". Therefore, emphasis was placed on ensuring transparency, open availability and wide dissemination throughout the process. Building credibility into the resource requires documenting every step undertaken to enable reproducibility of the final outcome [87]. In this regard, there are two questions worth considering: 1) Was the original study described in a transparent manner? and 2) Does the registry adequately reflect the information contained within the study? In order to address the first question, while standard quality assessment checklists and reporting standards such as the consolidated health economic evaluation reporting standards (CHEERS) guided our variable selection process, we did not formally assign a score for each study [88]. This is because, our registry was not restricted to full economic evaluations, but also included partial economic analysis such as CAs and cost of illness studies (COUP), elements of which may not be fully met by criteria mentioned in quality assessment checklists. Additionally, while all the studies essentially aimed to answer the question of the cost-effectiveness or savings that access to contraceptives can provide in various settings, the methodology and outcome measure used varied considerably among the studies, especially those conducted pre-2000 (Table 1). We, therefore, leave it to the researcher to decide whether estimates or conclusions derived from a particular study from the registry should be weighted differently as compared to another study for their individual research purposes.

Other well-known registries are good resources which document economic evaluations conducted on nondisease specific interventions $[4,5,7]$. A query using the term "contraceptive" on the Tufts CEA registry showed 15 studies, of which four were on contraceptives used for contraception, with the other studies focused on contraceptives used for other clinical conditions such as uterine fibroids, endometriosis and dysmenorrhea. The Tufts DALY study revealed one study and the NHS EED had 50 studies of which 20 were relevant to our clinical question. However, the Tufts CEA registry is not completely publicly accessible, and the NHS EED has discontinued updates and lacks a querying functionality. Therefore, we decided to create this specific, openaccess database that can be queried. This is also in response to calls from the health economics community advocating for greater transparency and openness in health economic evaluations [11, 89-93]. The features of our registry seem to address the barriers to utilization of cost-effectiveness models and meet the desirable features of such a database as assessed by Teerawattananon et al. during interviews of policymakers, technical advisors and researchers in Bangladesh, India and Vietnam [94].

Our registry offers a resource for researchers working in the field of family planning and reproductive health, which is an important component towards fulfilling the United Nations sustainable development goal 3 [95]. It was therefore not aimed at synthesizing information from methodologically similar studies, as is common in systematic reviews, rather the registry aimed to provide an all-encompassing overview of economic studies conducted among various methodologies. Systematic reviews on economic evaluations of contraceptives have been conducted by Mavranezouli [96] and Lynch et al. [97], with one considering family planning interventions in general in low and middle income countries conducted by Zakiyah et al. [98] Economic evaluations addressing contraceptives especially in developing country settings is lacking [96]. This remains an important challenge, since results of economic evaluations from developed countries may not be transferable to developing country settings, given the vastly different payment 


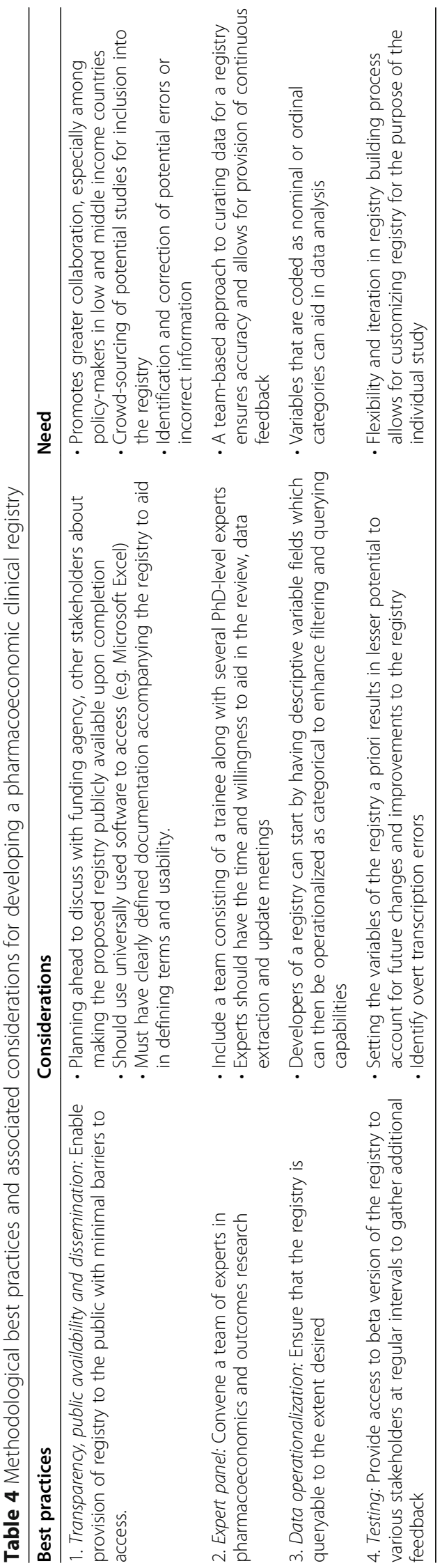


models (payer versus out of pocket) and contraceptive use patterns, among other differences $[19,99]$. While the number of studies conducted in the US was the most among other countries in our registry, a recent analysis revealed a lack of cost-utility analysis addressing the Healthy People 2020 priority areas, which includes reproductive and sexual health [100].

Our study had some limitations that can be addressed in future iterations of the registry. The CAs that were retrieved for the registry were only those identified from the database literature search, handsearching was not extensively conducted to identify other cost analyses. We did not include budget impact analyses and cost-consequences analyses in our registry. Other sources from which economic studies obtain their probabilities such as clinical trials or observational studies, or reports from the Guttmacher Institute [16], UN [19] and National Survey of Family Growth [101] were not included as they were not in the scope of our current registry.

\section{ConclusionGliklich RE, Dreyer NA, Leavy MB. Registries for evaluating patient outcomes: a user's guide. 3rd ed. Rockville (MD): Agency for}

The current paper provides a description of the development of a pharmacoeconomic clinical registry using a case study of economic evaluations conducted on hormonal contraceptives. The registry is a comprehensive database which provides key variables from all published economic literature relating to $\mathrm{HCs}$ and is hoped to serve as a tool that could aid in identifying global trends and avenues for future research and economic models. The development of best practices to appropriately design and execute a pharmacoeconomic clinical registry can provide helpful information to researchers and clinical practitioners for comparative effectiveness decision making. We invite the health economics community to make use of this resource for their own research purposes.

\footnotetext{
Abbreviations

QOL: Quality of life; RCT: Randomized control trials; DALY: Disability-Adjusted Life Year; QALY: Quality-adjusted life-year; NHS EED: National Health Service (NHS) Economic Evaluations Database; EURONHEED: European Network of Health Economic Evaluation Databases; WHO-CHOICE: WHO CostEffectiveness and Strategic Planning; HC: Hormonal contraceptives; DDI: Drug-drug interactions; CEA: Cost-effectiveness analyses, „CUA: Costutility analyses; CBA: Cost-benefit analyses; CMA: Cost-minimization analysis; COUP: Cost of unintended pregnancy; CA: Cost analyses; PRISMA: Preferred Reporting Items for Systematic Reviews and Meta-Analysis; LARC: Longacting reversible contraceptives; ACA: Affordable Care Act; OCs: Oral contraceptives; IUD: Intra uterine device; LNG: Levonorgestrel; MPA: Medroxyprogesterone acetate; CYP: Couple year of protection; DMPA: Depo-medroxyprogesterone acetate; IUS: Intra-uterine system; SARC: Short-acting reversible contraceptive; FPL: Federal poverty level; IM: Intra-muscular; SC: Subcutaneous; NICE: National Institute for Health and Care Excellence; NHS: National Health Service; OTC: Over the counter; NET-
}

EN: Norethisterone enanthate; VAS: Visual analog scale; TTO: Time trade-off; SG: Standard gamble

\section{Supplementary Information}

The online version contains supplementary material available at https://doi org/10.1186/s13561-021-00309-z.

\section{Additional file 1.}

Additional file 2.

Additional file 3.

Additional file 4

\section{Acknowledgements}

Not applicable.

\section{Authors' contributions}

AW designed and conceptualized the study. MS and AW were involved in the execution of the project and wrote the manuscript. LMW, SP and MF were a part of the expert panel and provided critical feedback on the manuscript. The authors read and approved the final manuscript.

\section{Funding}

This work was supported by a grant from the Bill \& Melinda Gates

Foundation.

Availability of data and materials

The datasets supporting the conclusions of this article and associated files are included within the article as supplementary information files.

\section{Declarations}

\section{Ethics approval and consent to participate}

Since publicly available data was used, the project received an "Exempt" status from the North Texas Regional Institutional Review Board, Fort Worth, TX.

\section{Consent for publication}

Not applicable.

\section{Competing interests}

The authors declare that they have no competing interests.

\section{Author details}

'University of North Texas System College of Pharmacy, University of North Texas Health Science Center, Fort Worth, TX 76107, USA. ${ }^{2}$ Department of Pharmacotherapy, UNT System College of Pharmacy, 3500 Camp Bowie Blvd, IREB 211, Fort Worth, TX 76107, USA. ${ }^{3}$ College of Pharmacy, Howard University, Washington, DC 20059, USA. ${ }^{4}$ Mercer University College of Pharmacy, Atlanta, GA 30341, USA.

Received: 17 August 2020 Accepted: 12 March 2021

Published online: 20 March 2021

\section{References}

1. Gliklich RE, Dreyer NA, Leavy MB. Registries for evaluating patient outcomes: a user's guide. 3rd ed. Rockville: Agency for Healthcare Research and Quality (US); 2014

2. Kennedy L, Craig A-M. Global registries for measuring Pharmacoeconomic and quality-of-life outcomes. Pharmacoeconomics. 2004;22(9):551-68. https://doi.org/10.2165/00019053-200422090-00001.

3. Clinical Trial Outcomes Databases. https://www.certara.com/solutions/clinica I-trial-outcome-databases/?ap=iDD\&UTM_LeadSource=. Accessed 05.02. 2020.

4. Nixon J, Stoykova B, Glanville J, Christie J, Drummond M, Kleijnen J. The U.K. $\mathrm{NHS}$ economic evaluation database. Economic issues in evaluations of health technology. Int J Technol Assess Health Care. 2000;16(3):731-42. https://doi.org/10.1017/S0266462300102016. 
5. The Cost-Effectiveness Analysis Registry. www.cearegistry.org. Accessed 11. 12.2019.

6. Greenberg D, Rosen AB, Wacht O, Palmer J, Neumann PJ. A bibliometric review of cost-effectiveness analyses in the economic and medical literature: 1976-2006. Med Decis Mak. 2010;30(3):320-7. https://doi.org/10.11 77/0272989X09360066.

7. Neumann PJ, Thorat T, Zhong Y, Anderson J, Farquhar M, Salem M, Sandberg E, Saret CJ, Wilkinson C, Cohen JT. A systematic review of costeffectiveness studies reporting cost-per-DALY averted. PLoS One. 2016; 11(12):e0168512. https://doi.org/10.1371/journal.pone.0168512.

8. Ungar WJ, Santos MT. The pediatric economic database evaluation (PEDE) project: establishing a database to study trends in pediatric economic evaluation. Med Care. 2003;41(10):1142-52. https://doi.org/10.1097/01.MLR. 0000088451.56688 .65 .

9. Nixon J, Ulmann P, Glanville J, Boulenger S, Drummond M, de Pouvourville G. The European network of health economic evaluation Databases (EURO NHEED) project. Eur J Health Econ. 2004;5(2):183-7. https://doi.org/10.1007/ s10198-003-0207-0.

10. Cost effectiveness and strategic planning (WHO-CHOICE). https://www.who. int/choice/en/.

11. Kent S, Becker F, Feenstra T, Tran-Duy A, Schlackow I, Tew M, Zhang P, Ye W, Lizheng S, Herman W, McEwan P, Schramm W, Gray A, Leal J, Lamotte $M$, Willis M, Palmer AJ, Clarke P. The challenge of transparency and validation in health economic decision modelling: a view from Mount Hood. Pharmacoeconomics. 2019;37(11):1305-12. https://doi.org/10.1007/s4 0273-019-00825-1.

12. Mount Hood Diabetes Challenge Network. https://www.mthooddiabetescha llenge.com/registry. Accessed May 6, 2020.

13. Bearak J, Popinchalk A, Alkema L, Sedgh G. Global, regional, and subregional trends in unintended pregnancy and its outcomes from 1990 to 2014: estimates from a Bayesian hierarchical model. Lancet Glob Health. 2018;6(4): e380-9. https://doi.org/10.1016/S2214-109X(18)30029-9.

14. Finer LB, Zolna MR. Declines in unintended pregnancy in the United States, 2008-2011. N Engl J Med. 2016;374(9):843-52. https://doi.org/10.1056/ NEJMsa1506575.

15. Sonfield A, Kost K. Public costs from unintended pregnancies and the role of public insurance programs in paying for pregnancy-related care: national and state estimates for 2010. New York: Guttmacher Institute; 2015.

16. Darroch JE. Adding it up: investing in contraception and maternal and newborn health, 2017-estimation methodology. New York: Guttmacher Institute; 2018

17. Trussell J. Understanding contraceptive failure. Best Pract Res Clin Obstet Gynaecol. 2009;23(2):199-209. https://doi.org/10.1016/j.bpobgyn.2008.11.008.

18. Sonfield A, Hasstedt K, Gold RB. Moving forward: family planning in the era of health reform. New York: Guttmacher Institute; 2014.

19. United Nations, Department of Economic and Social Affairs, Population Division. World Contraceptive Use 2019 (POP/DB/CP/Rev2019). 2019.

20. Akbar M, Berry-Bibee E, Blithe DL, Day RS, Edelman A, Höchel J, Jamshidi R, Kim MJ, Li L, Purohit VS, Turpin JA, Scott PE, Strauss DG, Sun H, Tepper NK, Zhang L, Yu C. FDA public meeting report on "drug interactions with hormonal contraceptives: public health and drug development implications". J Clin Pharmacol. 2018;58(12):1655-65. https://doi.org/10.1002/ jcph.1285.

21. Lesko LJ, Vozmediano V, Brown JD, Winterstein A, Zhao P, Lippert J, Höchel J, Chaturvedula A, White A, Schmidt S. Establishing a multidisciplinary framework to study drug-drug interactions of hormonal contraceptives: an invitation to collaborate. CPT Pharmacometrics Syst Pharmacol. 2018;7(11): 706-8. https://doi.org/10.1002/psp4.12357.

22. Kee WF, Tee QS. Singapore: a cost-effect analysis of a family planning program. Stud Fam Plan. 1972;3(1):8-11. https://doi.org/10.2307/1964714.

23. Ashraf T, Arnold S, Maxfield JM. Cost-effectiveness of levonorgestrel subdermal implants. Comparison with other contraceptive methods available in the United States. J Reprod Med. 1994;39(10):791-8.

24. Trussell J, Leveque JA, Koenig JD, London R, Borden S, Henneberry J, LaGuardia KD, Stewart F, Wilson TG, Wysocki S. The economic value of contraception: a comparison of 15 methods. Am J Public Health. 1995;85(4): 494-503. https://doi.org/10.2105/AJPH.85.4.494.

25. Hughes D, McGuire A. The cost-effectiveness of family planning service provision. J Public Health Med. 1996;18(2):189-96. https://doi.org/10.1093/ oxfordjournals.pubmed.a024479.
26. Trussell J, Koenig J, Stewart F, Darroch JE. Medical care cost savings from adolescent contraceptive use. Fam Plan Perspect. 1997;29(6):248-95. https:// doi.org/10.2307/2953412.

27. Phillips CJ. Economic analysis of long term reversible contraceptives. Pharmacoeconomics. 2000;17(2):209-21. https://doi.org/10.2165/00019053-2 00017020-00009.

28. French R, Cowan F, Mansour D, et al. Implantable contraceptives (subdermal implants and hormonally impregnated intrauterine systems) versus other forms of reversible contraceptives: two systematic reviews to assess relative effectiveness, acceptability, tolerability and cost-effectiveness. Health Technol Assess. 2000;4(7):1-107.

29. Nakhaee N, Mirahmadizadeh A, Gorji H, Mohammadi M. Assessing the costeffectiveness of contraceptive methods in shiraz, Islamic Republic of Iran. East Mediterr Health J. 2002;8(1):55-63.

30. Chiou C-F, Trussell J, Reyes E, Knight K, Wallace J, Udani J, Oda K, Borenstein J. Economic analysis of contraceptives for women. Contraception. 2003; 68(1):3-10. https://doi.org/10.1016/50010-7824(03)00078-7.

31. Varney SJ, Guest JF. Relative cost effectiveness of Depo-Provera ${ }^{\oplus}$, Implanon ${ }^{\odot}$, and Mirena in reversible long-term hormonal contraception in the UK. Pharmacoeconomics. 2004;22(17):1141-51. https://doi.org/10.2165/0001 9053-200422170-00004.

32. Sonnenberg FA, Burkman RT, Speroff L, Westhoff C, Hagerty CG. Costeffectiveness and contraceptive effectiveness of the transdermal contraceptive patch. Am J Obstet Gynecol. 2005;192(1):1-9. https://doi.org/1 0.1016/j.ajog.2004.09.004.

33. Mavranezouli I. The cost-effectiveness of long-acting reversible contraceptive methods in the UK: analysis based on a decision-analytic model developed for a National Institute for health and clinical excellence (NICE) clinical practice guideline. Hum Reprod. 2008;23(6):1338-45. https:// doi.org/10.1093/humrep/den091.

34. Trussell J, Lalla AM, Doan QV, Reyes E, Pinto L, Gricar J. Cost effectiveness of contraceptives in the United States. Contraception. 2009;79(1):5-14. https:// doi.org/10.1016/j.contraception.2008.08.003.

35. Lipetz C, Phillips CJ, Fleming CF. The cost-effectiveness of a long-acting reversible contraceptive $\left(\right.$ Implanon $\left.{ }^{\oplus}\right)$ relative to oral contraception in a community setting. Contraception. 2009;79(4):304-9. https://doi.org/10.101 6/j.contraception.2008.11.003

36. Ames CM, Norman WW. Preventing repeat abortion in Canada: is the immediate insertion of intrauterine devices postabortion a cost-effective option associated with fewer repeat abortions? Contraception. 2012;85(1): 51-5. https://doi.org/10.1016/j.contraception.2011.05.002.

37. Trussell J, Hassan F, Henry N, Pocoski J, Law A, Filonenko A. Costeffectiveness analysis of levonorgestrel-releasing intrauterine system (LNGIUS) 13.5 mg in contraception. Contraception. 2014;89(5):451-9. https://doi. org/10.1016/j.contraception.2013.10.019.

38. Han L, Teal SB, Sheeder J, Tocce K. Preventing repeat pregnancy in adolescents: is immediate postpartum insertion of the contraceptive implant cost effective? Am J Obstet Gynecol. 2014;211(1):24. e21-7.

39. Heitmann RJ, Mumford SL, Hill MJ, Armstrong AY. Estimated economic impact of the levonorgestrel intrauterine system on unintended pregnancy in active duty women. Mil Med. 2014;179(10):1127-32. https://doi.org/10.72 05/MILMED-D-14-00055.

40. Gariepy AM, Duffy JY. Cost-effectiveness of immediate compared with delayed postpartum etonogestrel implant insertion. Obstet Gynecol. 2015; 126(1):47-55. https://doi.org/10.1097/AOG.0000000000000907.

41. Trussell J, Hassan F, Lowin J, Law A, Filonenko A. Achieving cost-neutrality with long-acting reversible contraceptive methods. Contraception. 2015: 91(1):49-56. https://doi.org/10.1016/j.contraception.2014.08.011.

42. Canestaro W, Vodicka E, Downing D, Trussell J. Implications of employer coverage of contraception: cost-effectiveness analysis of contraception coverage under an employer mandate. Contraception. 2017;95(1):77-89. https://doi.org/10.1016/j.contraception.2016.08.002.

43. Agostini A, Godard C, Laurendeau C, Benmahmoud A, Lafuma A, Doz M, Lévy-Bachelot L, Gourmelen J, Linet T. Effectiveness and cost of contraception in France (FACET study): a cohort study from the French National Healthcare Insurance Database. Eur J Obstet Gynecol Reprod Biol. 2018;229:137-43. https://doi.org/10.1016/j.ejogrb.2018.08. 007.

44. Sonnenberg FA, Burkman RT, Hagerty CG, Speroff L, Speroff T. Costs and net health effects of contraceptive methods. Contraception. 2004;69(6):447-59. https://doi.org/10.1016/j.contraception.2004.03.008. 
45. Babigumira JB, Stergachis A, Veenstra DL, Gardner JS, Ngonzi J, MukasaKivunike P, Garrison LP. Potential cost-effectiveness of universal access to modern contraceptives in Uganda. PLoS One. 2012;7(2):e30735. https://doi. org/10.1371/journal.pone.0030735.

46. Burlone S, Edelman AB, Caughey AB, Trussell J, Dantas S, Rodriguez MI. Extending contraceptive coverage under the affordable care act saves public funds. Contraception. 2013;87(2):143-8. https://doi.org/10.1016/j. contraception.2012.06.009.

47. Henry N, Hawes C, Lowin J, Lekander I, Filonenko A, Kallner HK. Costeffectiveness analysis of a low-dose contraceptive levonorgestrel intrauterine system in Sweden. Acta Obstet Gynecol Scand. 2015;94(8):88490. https://doi.org/10.1111/aogs.12679.

48. Washington $\mathrm{Cl}$, Jamshidi R, Thung SF, Nayeri UA, Caughey AB, Werner EF. Timing of postpartum intrauterine device placement: a cost-effectiveness analysis. Fertil Steril. 2015;103(1):131-7. https://doi.org/10.1016/j.fertnstert.2 014.09.032.

49. Di Giorgio L, Mvundura M, Tumusiime J, Morozoff C, Cover J, Drake JK. Is contraceptive self-injection cost-effective compared to contraceptive injections from facility-based health workers? Evidence from Uganda. Contraception. 2018;98(5):396-404. https://doi.org/10.1016/j.contraception.2 018.07.137.

50. Gumbie M, Parkinson B, Cutler H, Gauld N, Mumford V. Is reclassification of the Oral contraceptive pill from prescription to pharmacist-only cost effective? Application of an economic evaluation approach to regulatory decisions. PharmacoEconomics. 2019;37(8):1049-64. https://doi.org/10.1007/ s40273-019-00804-6.

51. Rodriguez MI, Hersh A, Anderson LB, Hartung DM, Edelman AB. Association of pharmacist prescription of hormonal contraception with unintended pregnancies and medicaid costs. Obstet Gynecol. 2019;133(6):1238-46. https://doi.org/10.1097/AOG.0000000000003265.

52. Mvundura M, Di Giorgio L, Morozoff C, Cover J, Ndour M, Drake JK. Costeffectiveness of self-injected DMPA-SC compared with health-workerinjected DMPA-IM in Senegal. Contraception. 2019;1:100012. https://doi. org/10.1016/j.conx.2019.100012.

53. Ortmeier B, Sauer K, Langley P, Bealmear B. A cost-benefit analysis of four hormonal contraceptive methods. Clin Ther. 1994;16(4):707-13.

54. Foster DG, Rostovtseva DP, Brindis CD, Biggs MA, Hulett D, Darney PD. Cost savings from the provision of specific methods of contraception in a publicly funded program. Am J Public Health. 2009;99(3):446-51. https://doi. org/10.2105/AJPH.2007.129353.

55. Rodriguez MI, Caughey AB, Edelman A, Darney PD, Foster DG. Cost-benefit analysis of state-and hospital-funded postpartum intrauterine contraception at a university hospital for recent immigrants to the United States. Contraception. 2010;81(4):304-8. https://doi.org/10.1016/j.contraception.2 009.11.002.

56. Onwujekwe O, Ogbonna C, Ibe O, Uzochukwu B. Willingness to pay and benefit-cost analysis of modern contraceptives in Nigeria. Int J Gynaecol Obstet. 2013;122(2):94-8. https://doi.org/10.1016/j.ijgo.2013. 03.024.

57. Foster DG, Biggs MA, Malvin J, Bradsberry M, Darney P, Brindis CD. Costsavings from the provision of specific contraceptive methods in 2009. Womens Health Issues. 2013;23(4):e265-71. https://doi.org/10.1016/j.whi.2 013.05.004.

58. Keen S, Begum H, Friedman HS, James CD. Scaling up family planning in Sierra Leone: a prospective cost-benefit analysis. Womens Health (Lond). 2017;13(3):43-57. https://doi.org/10.1177/1745505717724617.

59. Concepcion K, Lacey S, McGeechan K, Estoesta J, Bateson D, Botfield J. Cost-benefit analysis of enhancing the uptake of long-acting reversible contraception in Australia. Aust Health Rev. 2019;44(3):385.

60. Wilkinson TA, Downs SM, Edmonds BT. Cost minimization analysis of sameday long-acting reversible contraception for adolescents. JAMA Netw Open. 2019;2(9):e1911063. https://doi.org/10.1001/jamanetworkopen.2019.11063.

61. Janowitz B, Kanchanasinith K, Auamkul N, Amornwichet P, Soonthorndhada K, Hanenberg R. Introducing the contraceptive implant in Thailand: impact on method use and costs. Int Fam Plan Perspect. 1994;20(4):131-6. https:// doi.org/10.2307/2133257.

62. Koenig JD, Strauss MJ, Henneberry J, Wilson TG. The social costs of inadequate contraception. Int J Technol Assess Health Care. 1996;12(3): 487-97.

63. Margulies R, Miller L. Increased depot medroxyprogesterone acetate use increases family planning program pharmaceutical supply costs.
Contraception. 2001;63(3):147-9. https://doi.org/10.1016/S0010-7824(01)001 85-8.

64. Lipetz C, Fleming C, Phillips C. Actual cost of providing long-acting reversible contraception: a study of Implanon ${ }^{\circledast}$ cost. BMJ Sex Reprod Health. 2009;35(2):75-9.

65. Tumlinson K, Steiner MJ, Rademacher KH, Olawo A, Solomon M, Bratt J. The promise of affordable implants: is cost recovery possible in Kenya? Contraception. 2011;83(1):88-93. https://doi.org/10.1016/j.contraception.201 0.06.016.

66. Chin-Quee D, Bratt J, Malkin M, Nduna MM, Otterness C, Jumbe L, Mbewe RK. Building on safety, feasibility, and acceptability: the impact and cost of community health worker provision of injectable contraception. Glob Health Sci Pract. 2013;1(3):316-27. https://doi.org/10.9745/GHSP-D-13-00025.

67. Salcedo J, Sorensen A, Rodriguez MI. Cost analysis of immediate postabortal IUD insertion compared to planned IUD insertion at the time of abortion follow up. Contraception. 2013;87(4):404-8. https://doi.org/10.1016/j.contra ception.2012.11.011.

68. Cook L, Fleming C. What is the actual cost of providing the intrauterine system for contraception in a UK community sexual and reproductive health setting? Fam Plann Reprod Health Care. 2014;40(1):46-53. https://doi. org/10.1136/jfprhc-2012-100377.

69. Schnippel K, Lince-Deroche N, van den Handel T, Molefi S, Bruce S, Firnhaber C. Cost evaluation of reproductive and primary health care mobile service delivery for women in two rural districts in South Africa. PLoS One. 2015;10:3

70. Chola L, McGee S, Tugendhaft A, Buchmann E, Hofman K. Scaling up family planning to reduce maternal and child mortality: the potential costs and benefits of modern contraceptive use in South Africa. PLoS One. 2015:10:6

71. Foster DG, Biggs MA, Phillips KA, Grindlay K, Grossman D. Potential public sector cost-savings from over-the-counter access to oral contraceptives. Contraception. 2015;91(5):373-9. https://doi.org/10.1016/j.contraception.201 5.01.010.

72. Rademacher $\mathrm{KH}$, Solomon $\mathrm{M}$, Brett $\mathrm{T}$, et al. Expanding access to a new, more affordable levonorgestrel intrauterine system in Kenya: service delivery costs compared with other contraceptive methods and perspectives of key opinion leaders. Glob Health Sci Pract. 2016;4(Supplement 2):S83-93.

73. Law A, McCoy M, Lingohr-Smith M, Lin J, Lynen R. Modeled cost differences associated with use of Levonorgestrel intrauterine devices. Am J Pharm Benefits. 2017:9(1):12-7.

74. Madden T, Barker AR, Huntzberry $K$, et al. Medicaid savings from the Contraceptive CHOICE Project: a cost-savings analysis. Am J Obstet Gynecol. 2018;219(6):595. e591-11.

75. Schwarz EB, Smith R, Steinauer J, Reeves MF, Caughey AB. Measuring the effects of unintended pregnancy on women's quality of life. Contraception. 2008;78(3):204-10. https://doi.org/10.1016/j.contraception.2008.04.120.

76. Lundsberg LS, Xu X, Schwarz EB, Gariepy AM. Measuring health utility in varying pregnancy contexts among a diverse cohort of pregnant women. Contraception. 2017;96(6):411-9. https://doi.org/10.1016/j.contraception.201 7.08.003.

77. Henry N, Schlueter M, Lowin J, Lekander I, Filonenko A, Trussell J, Skjeldestad FE. Cost of unintended pregnancy in Norway: a role for longacting reversible contraception. J Fam Plann Reprod Health Care. 2015;41(2): 109-15. https://doi.org/10.1136/jfprhc-2014-100878.

78. Engstrand S, Kallner HK. Cost of unintended pregnancy in Sweden-a possibility to lower costs by increasing LARC usage. Contraception. 2018; 97(5):445-50. https://doi.org/10.1016/j.contraception.2018.01.009.

79. Le HH, Connolly MP, Yu J, Pinchevsky Y, Steyn PS. The public health and economic consequences of unintended pregnancies in South Africa. Healthc Low-Resour Settings. 2015;3:1.

80. Trussell J, Henry N, Hassan F, Prezioso A, Law A, Filonenko A. Burden of unintended pregnancy in the United States: potential savings with increased use of long-acting reversible contraception. Contraception. 2013; 87(2):154-61. https://doi.org/10.1016/j.contraception.2012.07.016.

81. Trussell J. The cost of unintended pregnancy in the United States. Contraception. 2007;75(3):168-70. https://doi.org/10.1016/j.contraception.2 006.11.009.

82. Montouchet C, Trussell J. Unintended pregnancies in England in 2010: costs to the National Health Service (NHS). Contraception. 2013;87(2):149-53. https://doi.org/10.1016/j.contraception.2012.06.008.

83. Lete I, Hassan F, Chatzitheofilou I, Wood E, Mendivil J, Lambrelli D, Filonenko A. Direct costs of unintended pregnancy in Spain. Eur J 
Contracept Reprod Health Care. 2015;20(4):308-18. https://doi.org/10.31 09/13625187.2015.1028617.

84. Black AY, Guilbert E, Hassan F, Chatziheofilou I, Lowin J, Jeddi M, Filonenko A, Trussell J. The cost of unintended pregnancies in Canada: estimating direct cost, role of imperfect adherence, and the potential impact of increased use of long-acting reversible contraceptives. J Obstet Gynaecol Can. 2015;37(12):1086-97. https://doi.org/10.1016/S1701-2163(16)30074-3.

85. Lowin J, Jarrett J, Dimova M, Ignateva V, Omelyanovsky V, Filonenko A. Direct costs of unintended pregnancy in the Russian Federation. Appl Health Econ Health Policy. 2015;13(1):61-8. https://doi.org/10.1007/s40258014-0131-8.

86. Dieguez G, Pyenson BS, Law AW, Lynen R, Trussell J. The cost of unintended pregnancies for employer-sponsored health insurance plans. Am Health Drug Benefits. 2015;8(2):83-92.

87. Eddy DM, Hollingworth W, Caro JJ, Tsevat J, McDonald KM, Wong JB. Model transparency and validation: a report of the ISPOR-SMDM modeling good research practices task force-7. Med Decis Mak. 2012;32(5):733-43. https:// doi.org/10.1177/0272989X12454579.

88. Husereau D, Drummond M, Petrou S, Carswell C, Moher D, Greenberg D, Augustovski F, Briggs AH, Mauskopf J, Loder E, CHEERS Task Force. Consolidated health economic evaluation reporting standards (CHEERS) statement. Int J Technol Assess Health Care. 2013;29(2):117-22. https://doi. org/10.1017/S0266462313000160.

89. Catalá-López F, Caulley L, Ridao M, et al. Reproducible research practices, openness and transparency in health economic evaluations: study protocol for a cross-sectional comparative analysis. BMJ Open. 2020;10:2.

90. Center for the Evaluation of Value and Risk in Health. Open-Source Model Clearinghouse. http://ghcearegistry.com/orchard/open-source-model-clea ringhouse. Accessed May 11, 2020.

91. Tappenden P, Caro JJ. Improving transparency in decision models: current issues and potential solutions. Pharmacoeconomics. 2019;37(11):1303-4. https://doi.org/10.1007/s40273-019-00850-0.

92. Arnold RJ, Ekins S. Ahead of our time: collaboration in modeling then and now. Pharmacoeconomics. 2017;35(9):975-6. https://doi.org/10.1007/s40273017-0532-2.

93. Wu EQ, Zhou Z-Y, Xie J, Metallo C, Thokala P. Transparency in health economic modeling: options, issues and potential solutions. PharmacoEconomics. 2019;37(11):1349-54. https://doi.org/10.1007/s40273019-00842-0.

94. Teerawattananon Y, Tantivess S, Yamabhai I, Tritasavit N, Walker DG, Cohen JT, Neumann PJ. The influence of cost-per-DALY information in health prioritisation and desirable features for a registry: a survey of health policy experts in Vietnam, India and Bangladesh. Health Res Policy Syst. 2016;14(1): 86. https://doi.org/10.1186/s12961-016-0156-6.

95. United Nations. Sustainable Development Goals. https://sustaina bledevelopment.un.org/?menu=1300. .

96. Mavranezouli I. Health economics of contraception. Best Pract Res Clin Obstet Gynaecol. 2009;23(2):187-98. https://doi.org/10.1016/j.bpobgyn.2 008.11.007.

97. Lynch M, De Abreu LR, Flattery M, Haas M. Reviewing the cost-effectiveness of long-acting reversible contraceptive methods in an Australian context. Aust N Z J Obstet Gynaecol. 2019;59(1):21-35. https://doi.org/10.1111/ajo.12906.

98. Zakiyah N, van Asselt AD, Roijmans F, Postma MJ. Economic evaluation of family planning interventions in low and middle income countries; a systematic review. PLoS One. 2016;11:12.

99. Goeree R, Burke N, O'Reilly D, Manca A, Blackhouse G, Tarride J-E. Transferability of economic evaluations: approaches and factors to consider when using results from one geographic area for another. Curr Med Res Opin. 2007;23(4):671-82. https://doi.org/10.1185/030079906X167327.

100. Neumann PJ, Farquhar M, Wilkinson CL, Lowry M, Gold M. Lack of costeffectiveness analyses to address healthy people 2020 priority areas. Am J Public Health. 2016;106(12):2205-7. https://doi.org/10.2105/AJPH.2016.303361.

101. Centers for Disease Control and Prevention. National Center for Health Statistics. Key Statistics from the National Survey of Family Growth. https://www.cdc.gov/nchs/nsfg/key_statistics_2015_2017.htm. Accessed May 8, 2020.

\section{Publisher's Note}

Springer Nature remains neutral with regard to jurisdictional claims in published maps and institutional affiliations.

\section{Ready to submit your research? Choose BMC and benefit from}

- fast, convenient online submission

- thorough peer review by experienced researchers in your field

- rapid publication on acceptance

- support for research data, including large and complex data types

- gold Open Access which fosters wider collaboration and increased citations

- maximum visibility for your research: over $100 \mathrm{M}$ website views per year

At BMC, research is always in progress.

Learn more biomedcentral.com/submissions 